Etnográfica

Revista do Centro em Rede de Investigação em

Antropologia

vol. $13(1) \mid 2009$

Vol. $13(1)$

\title{
Contação de "causos" e negociação da verdade entre os Ave de Jesus, Juazeiro do Norte - CE
}

Telling "histories" ("causos") and negotiation of meaning and truth among The Ave de Jesus, Juazeiro do Norte - CE

\section{Roberta Bivar C. Campos}

\section{CpenEdition}

\section{Journals}

Edição electrónica

URL: https://journals.openedition.org/etnografica/1205

DOI: 10.4000/etnografica.1205

ISSN: 2182-2891

\section{Editora}

Centro em Rede de Investigação em Antropologia

Edição impressa

Data de publição: 2 maio 2009

Paginação: 31-47

ISSN: 0873-6561

\section{Refêrencia eletrónica}

Roberta Bivar C. Campos, "Contação de "causos" e negociação da verdade entre os Ave de Jesus, Juazeiro do Norte - CE», Etnográfica [Online], vol. 13 (1) | 2009, posto online no dia 16 março 2012, consultado o 12 fevereiro 2022. URL: http://journals.openedition.org/etnografica/1205 ; DOI: https:// doi.org/10.4000/etnografica.1205

\section{(c) (i) (8)}

Etnográfica is licensed under a Creative Commons Attribution-NonCommercial 4.0 International License. 


\section{Contação de "causos" e negociação da verdade entre os Ave de Jesus, Juazeiro do Norte - CE}

\section{Roberta Bivar C. Campos}

O presente artigo está baseado no caso etnográfico dos Ave de Jesus, penitentes do Nordeste brasileiro, e tem por foco a discussão sobre a negociação de significados e validação da verdade entre pesquisador e pesquisados. Através da retomada do tema, clássico na antropologia, das crenças e da racionalidade, incluo na discussão o espaço de interlocução próprio da relação pesquisador-objetos/sujeitos, como parte da definição da situação onde são elaborados sentidos e significados da realidade.

PALAVRAS-CHAVE: “causos”, narrativas, negociação da verdade e significados, interlocução, dialogia.

\section{CONTANDO "CAUSOS": BUSCANDO SENTIDOS}

Pretendo explorar neste artigo a negociação de significados e da verdade nos "causos" a mim contados pelos Ave de Jesus, membros de um grupo de penitentes que vivem sob o voto de pobreza e castidade, em Juazeiro do Norte (Ceará), no Nordeste brasileiro, região do Cariri. Um "causo" é um tipo de narrativa popular encontrada, mais frequentemente, no Nordeste brasileiro. A maneira como se conta um "causo" lembra o estilo da lenda. É narrado como quem conta uma história que começa com "Era uma vez...", explorando o humor do inusitado, mas que tem a intenção de relatar um evento passado e uma mensagem verdadeira e de valor moral.

O interesse por tal questão surgiu durante meu trabalho de campo, quando me vi forçada a lidar com questões sobre ficção, metáfora e sentido literal. A questão interpretativa não se limitava ao fato de lidar com eventos 
extraordinários que não faziam parte de minhas crenças. Mais do que isso: tratava-se do desafio de lidar com estilos narrativos que parecem não respeitar a diferença entre ficção e realidade ou entre sentido literal e metafórico, e que tampouco evocam seriedade para atribuição de credibilidade às afirmações. As questões que se colocavam eram: quais os critérios de verdade do grupo? Apesar de os "causos", por sua natureza híbrida, serem ordenados por critérios de verdade distintos daqueles da racionalidade "hegemônica" (moderna), os "causos" contados pelos Ave de Jesus pareciam evocar critérios também utilizados por essa racionalidade.

Joanna Overing (1985) e Barley (1983) observam que os antropólogos modernos, num esforço em afirmar a racionalidade do nativo, mesmo fugindo ao etnocentrismo, sempre tenderam a traduzir aquilo que lhes parecia absurdo como metáforas elaboradas pelos nativos. Um outro ponto, agora salientado por Cohen e Rapport (1995), é que a antropologia tem assumido como dada a consciência do nativo, em geral tratando-a como derivada de uma estrutura social ou como correspondente direta de uma "consciência coletiva", sem questionar suas particularidades, e assim acaba impondo suas representações do que seria a consciência no outro. Os autores então perguntam: como saber do que as pessoas são conscientes? Existe tal fenômeno, a consciência coletiva? E como a consciência individual interage com esta? E, ainda, qual a natureza do encontro entre a consciência do nativo e do antropólogo?

Fernandez (1995) nos auxilia a tratar dessas questões tão difíceis sobre o encontro etnográfico e a produção do conhecimento antropológico, sem que tudo se reduza à textualização, como acontece em muitos autores inspirados pelo livro Writing Culture (Clifford e Marcus 1986). Para James Fernandez, existe razão suficiente para duvidarmos da possibilidade de realmente conhecer a mente do outro. O que na realidade aprendemos é o resultado do encontro entre a consciência do antropólogo e a do nativo. Dessa forma, o que temos é uma formulação secundária, resultante da necessidade que os indivíduos têm de se acomodarem às expectativas exteriores, e não a verdadeira e original consciência pré-objetiva. ${ }^{1}$ A consciência emerge, assim, de circunstâncias sociais e num espaço público, sendo então produto da necessidade de comunicação com o outro. Aquela a que o antropólogo tem acesso é a que foi disponibilizada em conversas e através de atitudes no processo em que antropólogo e interlocutores interagem em conversação. É, assim, produto de uma praxis, de uma adaptação social, e não tem nenhum antecedente possível de ser investigado (Fernandez 1995). A investigação da verdadeira consciência nativa pode ser impossível, mas, por outro lado, toda a dinâmica do processo criativo pelo qual os indivíduos praticam a consciência de si continua e deve ser investigada 
pelos antropólogos. É nesse sentido que a negociação dos significados e do que é verdadeiro nos "causos" torna-se relevante.

E sobre isso torna-se imprescindível levar a sério o que o nativo nos diz, e não simplesmente traduzir o que é absurdo para nós como metáforas. É preciso romper com esse tipo de textualização da cultura, tomando o caminho do que Bruno Latour $(2002 ; 2008)$ chama de antropologia simétrica. Seguir este caminho possibilita romper com a atitude generalizada de que os "nativos" acreditam e nós antropólogos sabemos e conhecemos (Overing 1985; Latour 2002; 2008; Viveiros de Castro 2002). É seguindo esta proposta, sem me converter em Ave de Jesus, que explorarei nas páginas seguintes meus dados de campo. Parte desses dados decorre de anotações no diário de campo, o que, de alguma forma, me obriga ao uso da narrativa indireta, rompendo com a dialogia (Clifford 2002). Todavia, procuro manter a polifonia, tentando, dentro do possível, aproximar-me, nesses momentos, da linguagem de meus interlocutores. Viveiros de Castro (2002) e Clifford (2002) já alertaram para os limites da dialogia, lembrando que, em última instância, quem interpreta (e aqui acrescento: mesmo que em co-autoria), textualiza, montando e editando os dados é o antropólogo:

A relação diferencial do antropólogo e o nativo com suas culturas respectivas e portanto com suas culturas recíprocas, é de tal ordem que a igualdade de fato não implica uma igualdade de direito - uma igualdade no plano do conhecimento. O antropólogo tem usualmente uma vantagem epistemológica sobre o nativo. $\mathrm{O}$ discurso do primeiro não se acha situado no mesmo plano que o discurso nativo, mas é ele quem detém o sentido desse sentido - ele quem explica e interpreta, traduz e introduz, textualiza e contextualiza, justifica e significa esse sentido. A matriz relacional do discurso antropológico é hilemórfica: o sentido do antropólogo é forma; o do nativo, matéria. O discurso do nativo não detém o sentido de seu próprio sentido. De fato, como diria Geertz, somos todos nativos; mas de direito, uns sempre são mais nativos que outros (Viveiros de Castro 2002: 115).

Um outro ponto importante para a compreensão do meu caminho interpretativo é lembrar a observação de Latour (2008) de que antes das palavras existem as coisas e as relações entre elas. Este talvez seja o ponto fundamental de meu artigo: a articulação entre o espaço de interlocução (entre pesquisador e pesquisados) e o habitus cultural (Sahlins 1999) dos Ave de Jesus, isto é, a "cultura bíblica" (Velho 1995). Não quero cair presa de nenhuma sobreposição entre estes planos; a minha intenção é mostrar as articulações entre um e outro. 


\section{Um pouco sobre "causos" e "cultura bíblica"}

À medida que os Ave de Jesus me contavam seus "causos" e cantavam seus benditos, ${ }^{2}$ dei-me conta de alguns elementos bastante recorrentes nestas narrativas. Primeiramente, relatar um evento ou defender um preceito moral, entre os Ave de Jesus, vem em geral acompanhado de cuidado estético. Ao lado do esforço caprichoso com o belo, observei que, nos "causos" contados, as entidades divinas têm participação histórica nos eventos locais e, quando os Ave de Jesus contam algum "causo" sobre algum milagre, é bastante recorrente a menção da presença, no local do evento, de um amigo, parente, conhecido ou daquele mesmo que relata o evento. ${ }^{3}$ Mais precisamente, chamou-me a atenção o fato de a intervenção divina ou a comunicação da divindade com os fiéis não se fazer unicamente, como em muitos outros relatos de aparições em outras regiões do Brasil, através de uma experiência mística ou espiritual. Ao contrário, as entidades divinas são personagens encarnadas historicamente. Esse outro tipo de "aparição" ou contato com entidades místicas, ou as chamadas visões em Juazeiro do Norte, nos leva a uma visão de mundo particular, onde os sujeitos se entendem a si próprios e a sua história como parte do desenrolar de eventos de uma narrativa verdadeiramente bíblica (Velho 1995).

Há em Juazeiro uma cultura de milagres e aparições onde se destaca a materialidade histórica das entidades e imagens bíblicas (a paixão, a mendicância, etc.), tornando o conceito de "cultura bíblica" fundamental para compreender como as imagens bíblicas e a paisagem geográfica se fundem e se projetam como categorias de construção do real. A "cultura bíblica", como é definida por Velho (1995), representa um complexo de símbolos e imagens originários da Bíblia, que funcionam como uma referência para o pensamento e a ação. Steil, por sua vez, mostra em seu estudo sobre a romaria ao Santuário de Bom Jesus da Lapa, sertão baiano, como os personagens e a geografia local são identificados com os mitos e a Bíblia; ainda segundo esse autor, através de representações bíblicas, os romeiros estabelecem uma relação entre a experiência presente e o passado dentro do contexto sertanejo (Steil 1996: 17).

Em verdade, muitos estudos tentam mostrar o papel que a evangelização da Igreja do período colonial desempenhou no surgimento e no desenvolvimento de tais formas de crenças, ou seja, na sacralização da geografia e da história locais, através de um processo de identificação entre personagens, lugares históricos e imagens bíblicas. É importante salientar, entretanto, que não se está aqui afirmando a determinação da evangelização sobre a religiosidade popular

2 Tipo de reza cantada, comum no interior do Brasil, em especial na cultura popular do Nordeste brasileiro.

3 Candice Slater (1986), em sua tese de doutoramento, também observou a referência a testemunhas oculares nos "causos" em Juazeiro do Norte - CE. 
sertaneja. Sahlins (1999), através do episódio do Capitão Cook, já nos ensinou como a história é estruturada culturalmente.

Portanto, devemos considerar a força estrutural do interno, ou seja, da lógica cultural ou, no dizer da Sahlins (1999; 2004), de uma matriz simbólica, ou do habitus cultural local na constituição do externo (fatores externos ao grupo, como, por exemplo, a expansão do capitalismo, a globalização). De modo que tal forma de evangelização por si só não explica os seus efeitos (a crença de que Padre Cícero é Jesus, de que Juazeiro é Jerusalém, etc.). Snow et al. (1986), para dar conta das relações entre a lógica interna (habitus cultural à maneira de Sahlins) e sua relação com os fatores externos (globalização), entendem esse encontro como um frame alignment (alinhamento de marcos interpretativos) da realidade. No alinhamento dos marcos interpretativos internos e externos podem ocorrer processos de amplificação (frame amplification) de alguns aspectos já presentes no marco interpretativo dos "nativos". Nesse sentido, poderíamos imaginar que o mesmo processo ocorre entre o habitus cultural dos sertanejos e o da evangelização (globalização do cristianismo/catolicismo), favorecendo elementos, lógicas já latentes que se reforçam no encontro cultural levando à transformação do marco interpretativo anterior, tal qual no modelo de Sahlins (Snow et al. 1986).

Dessa forma, se podemos dizer que os Ave de Jesus herdaram dos portugueses a crença medieval no Quinto Império que seria governado sob o signo do Espírito Santo e da Coroa Portuguesa, não podemos esquecer que, mesmo antes dos portugueses, algumas tribos indígenas "já buscavam pela terra sem mal", "seguindo o primeiro profeta em terras brasileiras, o karai" (Clastres 1995).

Mas antes de adentrar na questão específica em que neste artigo quero tratar, é importante situar aqueles que servem de base para as minhas referências etnográficas.

\section{Milagre em Juazeiro}

Muitos sertanejos herdaram algumas crenças do catolicismo medieval português, como a prática da penitência e o Sebastianismo. ${ }^{4}$ Uma comunidade de penitentes, no Juazeiro do Ceará, chamada Ave de Jesus, vive essa tradição ao seu modo. A sua origem relaciona-se diretamente a um movimento messiânico de origem relativamente recente. Tudo começou no Juazeiro do Norte com a morte de Padre Cícero, em 1934.

4 Sebastianismo: crença no Quinto Império que seria governado pelo Espírito Santo e pela Coroa Portuguesa, que tem suas raízes na figura lendária de Dom Sebastião, Rei de Portugal no século XVI. De acordo com a lenda, Dom Sebastião desapareceu na batalha de Alcácer-Quibir, na África, em 4 de agosto de 1578, quando comandava as tropas portuguesas. A crença na sua divindade se fortaleceu a partir da versão de que seu corpo teria desaparecido, e desde então muitos passaram a esperar o seu retorno, quando ele traria redenção, salvação e felicidade. 
Todavia, pode ainda se reportar a tempos mais remotos. Por volta da Proclamação da República e da Romanização do Catolicismo no Brasil ${ }^{5}$ ocorreram eventos extraordinários em Juazeiro do Norte. Em 1889 a beata Maria de Araújo passou a ter experiências extáticas, caindo em transe, ao receber a hóstia de Padre Cícero, em comunhão, durante as missas. É dito também que as hóstias sangravam. Entretanto, foi só quatro anos depois da morte de Padre Cícero, em 1938, que uma forte e entusiástica devoção a sua figura começou. Após vários relatos de sua aparição, o milagre se espalhou do Cariri para todo o Brasil. Desde então, muitos esperam o retorno de Cícero, quando ele libertará seu povo, tal qual Dom Sebastião, de todo o sofrimento.

Foi assim que um homem nascido em Pernambuco, não se sabe, ao certo, se pequeno agricultor ou trabalhador rural ou mesmo comerciante, migrou para Juazeiro. Esse homem, mestre José, junto com outros Ave de Jesus, viveu nos arredores de Juazeiro em voto de castidade e pobreza esperando pelo final dos tempos, até a sua morte.

Esses penitentes e muitos outros penitentes e romeiros de Juazeiro do Norte acreditam viver em tempos bíblicos, sendo os eventos passados e atuais classificados e legitimados através de imagens do texto sagrado. Através desse acervo de imagens bíblicas, os Ave de Jesus explicam a realidade, ao mesmo tempo que utilizam para a validação de suas interpretações evidências materiais, como os fósseis de peixes encontrados no Sertão do Cariri que entendem como provas de que ali ocorreu o Dilúvio. Da mesma forma, afirmam que as pegadas de Maria e José são encontradas nos arredores de Juazeiro do Norte, ${ }^{6}$ o que evidencia, para eles, a presença das duas personagens bíblicas no Juazeiro. Uma outra forma de materialidade das crenças está na corporificação das divindades (Jesus Cristo e Nossa Senhora) em personagens históricas como Padre Cícero, que se acredita ser Jesus, e a mendicante chamada Mãe Ângela ("Anja”) do Horto, que se acredita ser Nossa Senhora.

Os Ave de Jesus, herdeiros de portugueses, índios e negros, por sua vez, expressam suas esperanças através de uma linguagem apocalíptica, composta por uma abundância de imagens concretas que funcionam como poderosas categorias conceptuais na interpretação e construção da realidade. Não estamos longe aqui do sentido dado por Lévi-Strauss, em O Pensamento Selvagem (1989 [1962]), ao uso de categorias concretas que funcionam como conceitos.

5 Romanização do Catolicismo refere-se ao processo reformador que visava a centralização do governo da Igreja Católica no Vaticano. Na prática, significou a integração dos cultos populares no catolicismo institucional. Através da centralização das práticas devocionais, a Igreja pretendia substituir o catolicismo organizado por irmandades e confrarias leigas por um catolicismo universalista, centrado na figura do padre. No Brasil esse modelo foi introduzido pelos bispos reformadores no século XIX.

6 Assim como para as pegadas de Maria e José, indicando que eles passaram por Juazeiro do Norte, há, segundo romeiros e fiéis de Padre Cícero, evidências materiais para a existência de eventos e lugares bíblicos como o Santo Sepulcro e a ocorrência do Dilúvio no Juazeiro do Norte. 


\section{A Etnografia}

Mestre José, antigo líder da comunidade de penitentes Ave de Jesus, contou-me que migrou para Juazeiro junto com a sua "costela", 7 comadre Regina, acompanhado por Nosso Senhor Jesus Cristo, nos idos dos anos 1970, quando Padre Cícero colocou em seu coração o desejo de ir à terra da Mãe de Deus.

De acordo com mestre José, chegando lá, ele e Regina conheceram uma penitente, a quem chamavam "Mãe Ângela (Anja) do Horto", que teria dito a eles para viverem da mendicância, chamarem a si mesmos Maria e José e vestirem azul e branco lembrando as dores de Nossa Senhora. Disse-me ainda mestre José que desde então passou a viver em Juazeiro, em companhia de Padrinho Cícero e Nossa Senhora Mãe das Dores, o que de fato fez até o dia de sua morte. Regina e todos aqueles que a eles se juntaram tornaram-se padrinhos e madrinhas, sendo tratados por comadres e compadres. Mais tarde Mãe Ângela do Horto seria reconhecida por eles como Nossa Senhora.

Mestre José também me contou que o "Sol lá em cima no céu é Deus", que clareia o dia e permite que as plantas cresçam e dêem frutos. Mas Deus é também o mesmo Sol, "a grande estrela" que seca as plantas levando o povo à fome e ao sofrimento. O Deus de quem fala mestre José é sem dúvida um deus moral; um deus heróico e impiedoso que, ao mesmo tempo que cria, destrói num ato violento de justiça.

Entendem os Ave de Jesus que, desde o ato da criação, a ordem divina foi estabelecida no mundo e mantida através do cumprimento da vontade de Deus, encontrada na Bíblia, fonte da Lei e da sabedoria. No entanto, o homem tem se corrompido pelo desejo material, levando à desordem do mundo. Nas palavras de mestre José,

Naquele tempo do Pai não se salvou ninguém não. Ele mandou o profeta Noé pregar. Ele pregou cem anos, não se converteu nenhum. Quer dizer que não se salvou nenhum dos cento e sessenta e cinco trilhões e meio. Aí ficou para esse novo texto... aí nesse novo texto taí desse jeito!

Jesus fez o homem santo... e o homem pecou para nós haver, o mundo. Então tinha de haver a República, a conformidade do engano da serpente...

A senhora não disse que é casada? Não tem seu marido? Olhe aí! Na República... no tribunal dos reis a senhora não podia fazer esse serviço [refere-se ao fato de eu estar trabalhando] e esse e outro que ele tá fazendo. Ele quem fazia para sustentar a senhora... os panos de sua casa. Ele é o Rei da senhora. Jesus é Rei de nós todos.

Deus é consolação dos sofridos. Deus é chefe-rei dos abandonados. Deus é Pai dos desgraçados, dos miseráveis...

7 A palavra costela é usada por mestre José em referência ao evento bíblico no livro do Gênesis, quando Deus faz a mulher, Eva, a partir da costela de Adão. 
A forma de socialidade baseada em relações de parentesco (autoridade, lealdade, reciprocidade, etc.) está de alguma maneira associada à concepção monárquica do mundo dos Ave de Jesus. Deus é Pai e Rei; Maria é Mãe e Rainha. Para mestre José, a separação entre Igreja e Estado pode ter acontecido historicamente, mas a monarquia permanece ainda viva como valor e sustenta uma verdade sagrada. O que se percebe em suas falas é que o modelo ideal patriarcalista, presente na monarquia, promete uma justiça social que ele não já encontrava nos dias correntes em que nos encontrávamos para conversar sobre suas crenças. É interessante observar que toda a Bíblia é uma espécie de coleção de histórias de reis e clãs; e assim, o livro sagrado funciona como acervo de imagens, conceitos, categorias de onde mestre José e outros Ave de Jesus retiram os modelos para ação e pensamento (Velho 1995).

É por esta razão que entendo que padrinho, pai e rei são categorias conceptuais. Não se limitam a fatos empíricos. São certamente categorias construídas tendo por referência a experiência, mas que são utilizadas num sentido mais geral e abstrato, diria melhor, são usadas como expressão de uma totalidade. Como explica Lévi-Strauss, em Mito e Significado, sobre o funcionamento de tais categorias,

Dizer que um modo de pensamento é desinteressado, e que é um modo inelectual de pensar, não significa que seja igual ao pensamento científico. Evidentemente que continua a ser diferente em certos aspectos, e que lhe é inferior noutros. E continua a ser diferente porque sua finalidade é atingir, pelos meios mais diminutos e econômicos, uma compreensão geral do universo - e não só uma compreensão geral, sim total. Isto é, trata-se de um modo de pensar que parte do princípio de que, se não se compreende tudo, não se pode explicar coisa alguma (Lévi-Strauss s/d.: 31, grifo meu).

A linguagem dos Ave de Jesus expressa uma visão de mundo em que o homem, a natureza e o profano estão infundidos e projetados numa dimensão sagrada, de tal forma que eles acreditam, melhor, dizem viver em um espaço e em um tempo bíblicos. Mestre José nos descreve assim uma Juazeiro mítica e sagrada, a única descrição possível de Juazeiro na sua visão e na de muitos outros romeiros que vão à Terra da Mãe de Deus, por devoção ao Padre Cícero. Com certeza, a visão dos Ave de Jesus de Juazeiro é bem diferente de uma geografia profana, que Eliade (1996) chama de "objetiva" e abstrata, apenas um espaço sem formas essenciais, nem conhecido nem habitado. Certamente Juazeiro não é tal espaço para Marias e Josés Ave de Jesus. Ao contrário, Juazeiro é essencial e concretamente infundida pelo sagrado e manifesta o extraordinário. Nas palavras de mestre José,

Adão foi de barro, e foi continuando a nação num cavaco, numa calha de cavaco, né? Num pé de serra dessa... no Horto... por aí. E onde é que a 
Nação pode ser terminada? Não é onde começou? Onde é que [estava] o pé de árvore que estimulou essa geração de 165 trilhões e meio? Aqui é o bico do compasso e da rotação do globo terrestre todo.

\section{Negociando a verdade}

Mas o campo não é sempre plano e sem contradições, já nos alertou Edmund Leach (1996). Os sentidos e significados são negociados na interação social, e também são criados na interação pesquisador-objeto, como também já comentou James Clifford (2002). Uma Juazeiro também se criou no espaço de interlocução que se estabeleceu entre mim e os Ave de Jesus. É sobre esse processo criativo em que nós antropólogas e antropólogos encontramos nossas metáforas e outros tropos para representação das culturas, das crenças e do modo de vida daqueles que pesquisamos que passo aqui a tratar. Todavia, a seguir também vou tentar conciliar o processo criativo que se estrutura na interação pesquisador-pesquisado e abordar a ação criativa de mestre José, entendendo-a como estruturada por uma lógica maior, no sentido bourdieusiano de um habitus religioso e cultural local, para além do espaço de interlocução pesquisador-objeto.

O trabalho de campo envolveu inúmeros encontros e muitas conversas. A maior parte das conversas com mestre José - algumas gravadas, outras não - deram-se em sua residência. Minha inserção no grupo se deu aos poucos. Não fui aceita imediatamente. Pouco a pouco ganhei a confiança dos Ave de Jesus. Mestre José foi o último a se convencer de que poderia confiar em mim. De forma que, em boa parte do campo, eles não me respondiam a tudo diretamente, sempre respondendo de forma evasiva quando eu perguntava sobre o seu passado. Só mais adiante, passados muitos encontros, foi que a relação tornou-se forte e eu me tornei "confiável”. Contudo, mestre José sempre soube, mais que os outros, que eu não compartilhava de suas crenças. Enquanto os outros Ave de Jesus tomavam suas crenças por dadas e naturais, não conseguindo conceber a existência do "outro", me relatavam com facilidade e sem receios as suas verdades. Mestre José, ocupando lugar diferenciado, por ter mais leitura e sabendo ler e escrever, de alguma forma, pôde compreender que apesar de eu não compartilhar suas crenças, eu o respeitava.

Quando mestre José me relatava a sua vinda de Pernambuco para Juazeiro nos idos dos anos 70, disse-me que recebeu uma espécie de chamado. Ao questioná-lo sobre a forma desse chamado, ele afirmou ter sido um pensamento. De seu quarto, sua esposa, dona Regina, logo interveio para melhor explicar: "Ele teve foi uma visão, minha filha. Foi, uma visão". No relato de dona Regina, mestre José, na verdade, tivera uma espécie de chamado místico, "uma espécie de visão", na qual Padre Cícero colocou, em seu coração, o desejo de ir para Juazeiro do Norte. A “contradição" é logo desfeita por mestre José, que nega a diferença entre visão e pensamento e argumenta que visão é uma espécie de "pensamento visível”. José, certamente, ao jogar com palavras elaborava metáforas 
e tentava, assim, negociar significados. Negociava significados para que não fosse julgado louco ou fanático, ao mesmo tempo que sustentava as suas crenças. Consciente de que as visões, no mundo de onde eu vinha, são interpretadas como coisa de louco ou de fanáticos, José tentava um diálogo com as minhas crenças e critérios de verdade (Campos 2001). Isto fica bastante claro em outro momento. Durante a renovação da fé,${ }^{8}$ tive a oportunidade de ouvir muitos dos benditos cantados pelos Ave de Jesus. Um deles chamou a minha atenção, pois sua letra dizia que São João Batista é o Menino Jesus. Antes mesmo que eu mencionasse qualquer coisa, mestre José calmamente disse para seu Olício, mestre da arte de cantar benditos: "Da próxima vez que você cantar esse bendito não diga São João Batista é o Menino Jesus, mas São João Batista e o Menino Jesus". Seu Olício então disse: "Huummm... mas ela [referindo-se a mim] sabe, compadre, que é verdade. Mas outros não entendem, né? Por que você [dirigindo-se a mim] entende, eu cantei do jeito certo."

José tentava, assim, um acordo sobre o que é plausível e verdadeiro com a sua interlocutora do mundo de fora, descrito por ele como "governado pelos falsos interesses do luxo e do progresso".

As crenças e práticas dos Ave de Jesus contrariam muitas das interpretações que vêem no catolicismo popular uma religião mágica, de "razão instrumental", voltada para a solução das aflições da vida diária. Aproximam-se muito mais de uma religião ascética e racional na tipologia weberiana. Por exemplo, os Ave de Jesus não realizam rituais de cura, entendem a benzenção como crendice. Mestre José afirmou: "Quem cura é Deus. Se ele não quiser, não adianta fazer nada." Entretanto, tal característica não impede que esses penitentes sejam vistos como fanáticos, loucos, ou mesmo bobos pela Igreja e por alguns moradores e turistas do Juazeiro do Norte. Entendo que isso muito se deve à corporificação de suas crenças através da ritualização de imagens bíblicas, como a Paixão. Se podemos dizer que a Igreja, em sua versão mais racionalizada, lê a Bíblia como metáfora, diremos que os Ave de Jesus vivem a Bíblia literalmente. Seus nomes são sagrados, as roupas que usam têm cores sagradas, os objetos que usam não podem ser de plástico, apenas de barro, e têm um modo de vida baseado na mendicância e no cultivo de uma horta comunal, regido por horas sagradas: na hora do Ângelus, todos fazem suas orações para, em seguida, se

8 A renovação da fé é um ritual bastante comum entre os Ave de Jesus. De acordo com eles, foi Padre Cícero quem "fundou” tal celebração. Esse ritual consiste em celebrar a conversão e/ou o batismo. Como muitas das celebrações religiosas, essa também toma parte da festa, na qual o profano e o sagrado se confundem, e é representada pela refeição oferecida aos convidados e membros dos Ave de Jesus. O dia da celebração varia de acordo com cada convertido. Normalmente é escolhido um dia santo para a celebração. Mestre José, por exemplo, celebrava a renovação de sua fé no dia do Sagrado Coração de Jesus (nove dias após o Corpus Christi). Nessa data especial, o celebrante deve deixar sua casa arrumada e limpa e oferecer alguma coisa para os convidados, "nem que seja um café com bolacha”, como me foi dito por uma das Ave de Jesus. 
recolherem. Acreditam viver onde tudo começou e onde tudo chegará ao fim, onde Maria teve seu filho e o viu ser crucificado. O uso de imagens através do corpo, mais do que a palavra falada, faz metáforas atravessarem fronteiras entre ficção e realidade, transformando o abstrato em concreto. Ao que parece, a confusão entre tais fronteiras também perturba os limites do que para alguns define o que seja racional. Enquanto que, para os Ave de Jesus, vivenciar literalmente as metáforas bíblicas é parte do próprio processo da construção da plausibilidade das afirmações que fazem sobre o mundo, na visão da Igreja e daqueles que pensam nos moldes mais "modernos" e "racionais" é justamente nessa corporificação/materialização de metáforas e imagens que reside a irracionalidade dos Ave de Jesus.

Mas o que interessa aqui é que, por outro lado, mestre José se mostrava consciente dessas diferenças e tentava validar sua narrativa através de critérios que julgava, talvez, me fossem mais plausíveis.

Mestre José combina números, imagens bíblicas, palavras que lembram o latim, outras relacionadas à história colonial (nomes de reis, etc.), outras provindas da ciência (rotação, geografia, geográfica, globo terrestre). Em uma de suas falas esse recurso se mostra claramente: "Quem fez nós, fez dividido. Duzentos e oito ossos, quinhentos e cinqüenta veias e duzentos e vinte componente[s] na cabeça para reunir com o coração."

O estilo da oratória de mestre José, sem dúvida, tem traços poéticos. É usando tal linguagem que ele dá força e entendimento ao que descreve, inspira credibilidade, fé e senso estético a muitos romeiros. Mestre José também é capaz de inventar palavras para dar conta da deficiência em seu vocabulário ou para fechar um pensamento, por exemplo, golal para cardeal, ou tibil para dar conta de que animais não têm alma. Quando lhe perguntei o que era tibil, ele me disse: "Tibil? Hum... não sabe? Tibil é uma palavra inglesa. É preciso saber para entender."

Se, por um lado, é a habilidade de dar sentido ao mundo através de uma linguagem particular que o torna especial para muitos devotos do "Padinho Ciço", por outro, é esta mesma linguagem, assim como seu corpo, que corporifica imagens sagradas, que o torna louco, bobo e fanático para muitos outros. A consciência de tais acusações coloca mestre José na fronteira entre sistemas de interpretação. Tal condição o força a negociar o significado de suas crenças, levando-o a inventar palavras, se não as tem, para dominar a retórica e negociar o sentido de outras.

Os truques de linguagem usados por mestre José estão próximos dos recursos encontrados no emprego de metáforas e metonímias para a transformação de noções concretas em idéias abstratas:

[...] a metáfora, logo, possibilita ao político explorar com sua platéia, novos modos de ver as coisas. Ele muda sua linha de argumentação, ou a 
visão que sua platéia tem dela. Ela é experimental e flexível, e é eficiente no ataque a posições já estabelecidas, transformando em idéias inteiras noções previamente separadas. A metonímia é conservadora por contraste. Ela se move em direção oposta e converte idéias em fenômenos tangíveis, eliminando, portanto, a possibilidade de que, por exemplo, as emoções possam ser úteis para que se pense, e realmente em outras culturas ela pode tomar o lugar de "razão". A metonímia pode, portanto, ser usada para defender uma posição política colocando-a acima da discussão. Ela estreita as opções conceituais (Parkin 1984: 356-357).

Observe-se que na passagem da narrativa sobre como vieram para o Juazeiro, "visão" foi usada por madrinha Regina no sentido literal. Mestre José, por sua vez, transforma "visão" em uma metáfora - "chamado visível", criando assim a flexibilidade de sentidos que essa expressão pode oferecer e, deste modo, cria também a possibilidade de negociação dos significados, significados estes que podem ser mais bem aceitos pelo que ele acredita ser meu sistema de interpretação, o que fica claro quando ele afirma: "Um chamado visível é um pensamento que dá na gente."

\section{Mas voltemos a José e a sua costela}

Ao tempo do acontecimento do "pensamento visível”, José era casado com Regina. Não tendo filhos, deixaram o pedaço de chão que tinham para trás e seguiram em peregrinação para Juazeiro do Norte. Como mestre José me falou, ele e "a sua costela seguiram então para Juazeiro". Apesar de eu não ter conseguido confirmar, entre os Ave de Jesus, se José e Regina eram camponeses ou pequenos agricultores, ficou bastante claro que eles queriam que eu assim acreditasse nesse momento. ${ }^{9}$ Essa intenção encontra sua razão no fato de os Ave de Jesus sustentarem a visão antiga e negativa da Igreja Católica sobre as atividades comerciais.

Todavia, fui informada pelo Padre Murilo e outros residentes de Juazeiro do Norte, de que José teria sido proprietário, em Juazeiro, de uma pequena mercearia, informação que será confirmada, indiretamente, pela própria madrinha Regina ao me contar um “causo". Padre Murilo ainda me informou de que José, antes de fundar a comunidade dos penitentes do Braço Sagrado de Jesus, os Ave de Jesus, fora um grande contador de "causos". José costumava contar "causos" sobre Padre Cícero debaixo de uma sombra de alguma árvore onde muita gente, penitentes e romeiros, se aglomerava para ouvi-lo. Mas não foi José quem me contou o "causo" que relato a seguir. Foi Regina quem mo contou.

9 Foi num momento de confiança entre mim e madrinha Regina que ela me revelou que mestre José fora dono de uma mercearia. Nas próximas páginas, quando relato a revelação de um “causo", guardado como segredo, por madrinha Regina a mim, esse fato do passado de mestre José é também relatado. 
No relato a seguir, veremos que as tentativas de negociação dos significados e o estilo narrativo de mestre José se apresentam como algo para além do espaço de interlocução com a pesquisadora. Isso nos sugere que a tentativa de inclusão de critérios mais racionais e objetivos faz parte de uma lógica, de uma agência criativa coletiva, é mais que um atributo, simplesmente, da inteligência e talento poético de mestre José, que ele certamente possui.

Em uma de minhas visitas à casa de mestre José e madrinha Regina - como então passaram a ser chamados -, esta me chamou. Ao chegar perto dela, pediu-me para que eu sentasse, pois tinha algo para me contar. Em suas mãos, madrinha Regina segurava um pequeno vestido azul. Um pouco perturbada com a situação, pensei que ela queria que eu me tornasse uma Ave de Jesus, mas, na verdade, à medida que ela me contava a história, eu me dava conta que aquele vestido tinha uma dona muito especial. Madrinha Regina então me relatou que, alguns dias após ter chegado a Juazeiro, começou a pensar em voltar para Pernambuco. Entretanto, os planos mudaram quando ela e mestre José tiveram um encontro com Mãe Ângela do Horto (Madrinha Ângela ou Mãe Anja), uma penitente que viveu no Juazeiro por muitos anos. Ela foi quem disse pessoalmente a mestre José que ele vivesse como penitente, lembrando àquela gente de Juazeiro as palavras do Senhor. Foi ela também quem lhe ensinou como viver na palavra do Senhor, como se vestir, que cores usar em suas roupas e o dever de viver da misericórdia (na mendicância). Mestre José não fez isso da noite para o dia. Ao que parece, viveu, juntamente com sua costela (comadre Regina) e com Madrinha Ângela, por um certo tempo, em uma casinha em algum lugar no Horto. Depois, então, vendeu sua mercearia $^{10}$ e sua casa e comprou um terreno no bairro de Tiradentes, na periferia de Juazeiro do Norte, onde fundou a comunidade dos Ave de Jesus. Madrinha Ângela do Horto vivia da caridade e morava numa casinha de taipa sem qualquer conforto. Disse-me ainda madrinha Regina que Madrinha Ângela sofreu, teve uma vida muito difícil, era uma mulher pequena e muito magrinha e foi muito piedosa. Madrinha Ângela separou-se desse mundo sem deixar qualquer pista do paradeiro de seu corpo. Porque ela levou uma vida tão sofrida e após a sua "morte" o seu corpo não foi achado, os Ave de Jesus acreditam que ela era Nossa Senhora. Para reforçar o caráter extraordinário do desaparecimento do corpo de Madrinha Ângela, madrinha Regina me disse que Madrinha Ângela lhe teria dito que ninguém neste mundo seria capaz de enterrá-la.

Tentei checar a existência de tal penitente que viveu no Horto, e mesmo a extensão da crença em sua santidade. Para minha surpresa, ou frustração, ninguém com que falei fora da comunidade dos Ave de Jesus sabia qualquer coisa sobre o assunto. Talvez isso fosse motivo suficiente para desconsiderar

10 Aqui o fato de mestre José ter sido proprietário de uma mercearia foi revelado por madrinha Regina, ao me revelar o encontro com Nossa Senhora, guardado pelo casal como "segredo". 
a importância etnográfica desse relato. Entretanto, tal história é bastante viva entre os Ave de Jesus, fazendo parte de seus rituais e cultos. Os Ave de Jesus, inclusive, mantêm ritos de celebração e benditos voltados ao culto de Madrinha Ângela do Horto. Até mais que isso, o grupo, tal como existe e se organiza, funda-se nos ensinamentos de Mãe ou Madrinha Ângela do Horto. Desconsiderar essa história seria desconsiderar as raízes míticas e simbólicas da fundação da comunidade Ave de Jesus. Mas, para além disso, algo me pareceu bastante provocador. A história de Madrinha Ângela do Horto, apesar de não ser um "causo" compartilhado amplamente por romeiros e penitentes, guarda semelhanças com outros "causos" mais conhecidos da comunidade de devotos do Padre Cícero.

Na história contada a mim por madrinha Regina, a vida de Madrinha Ângela repete algumas das circunstâncias da vida e morte de Jesus e Padre Cícero. Tal qual Jesus, Padre Cícero levou uma vida modesta e sem conforto. Tal qual Jesus e Padre Cícero, Madrinha Ângela foi sofredora e, assim, como eles, separou-se deste mundo e não morreu. A vida sofredora e modesta de Padre Cícero sempre aparece nos relatos como argumento a favor de sua santidade, assim como o desaparecimento do seu corpo, como acreditam romeiros e penitentes, é prova de sua separação deste mundo sem morte, tal qual Jesus. Madrinha era uma mulher sofredora, franzina, que viveu na pobreza, tendo morrido sem deixar pistas do paradeiro do seu corpo. Um outro elemento recorrente nessas histórias é o fato que tanto Padre Cícero como Madrinha Ângela são personagens históricas, ou seja, viveram neste mundo, na forma humana e material. Forte semelhança eles têm com Jesus. Jesus é filho de Deus encarnado historicamente, sua intervenção neste mundo não se dá unicamente por eventos extraordinários, representados pelos milagres, mas como possuidor de um corpo humano situado historicamente.

Madrinha Ângela é a Nossa Senhora encarnada na figura de uma penitente que, ao que parece, teve como missão passar alguns ensinamentos a madrinha Regina e mestre José. Padre Cícero é Jesus encarnado, assim acreditam romeiros e penitentes, e assim é relatado em um dos mais famosos "causos" de milagre em Juazeiro - "Nascimento de Padrinho Cícero e a troca misteriosa das crianças". Nesse "causo", Maria escolhe um anjo e através de uma artimanha substitui o filho recém-nascido de um casal do Crato, dona Joaquina Romana e Joaquim Romão Batista, pelo seu Salvador, para que fosse criado por eles. Cícero Romão Batista nascia para logo ser substituído por Jesus. Num folheto de cordel de autoria de João Cristo Rei, essa versão é confirmada:

Dona Joaquina Romana
Joaquim Romão Batista
São seus legítimos pais
Como a historia registra 
Mas pela lei da razão

só são pais de criação

(Cristo Rei s/d.).

Seu Olício, um dos Ave de Jesus, conhecido por seus benditos, me contou que as histórias extraordinárias que envolviam a vida de Padre Cícero se explicam muito bem pelo fato de ele ser Jesus. Padre Cícero ser Jesus já era fato conhecido de todos, disse-me ele, admirado de que eu desconhecia as circunstâncias do nascimento de Padre Cícero. E por isso resolveu que me contaria um "causo", pois assim, acreditava, eu passaria a entender tudo. Contou-me que logo que dona Romana deu à luz, Nossa Senhora, sorrateiramente, sem que fosse vista, trocou o bebê nascido pelo Menino Jesus. O pai de Cícero notou uma diferença nos bebês, e disse: "Mulher, esse menino não é nosso." A mulher, então, retrucou, dizendo que se aquele menino não fosse o deles, que ela ficasse cega. E, naquele momento, a mãe de Padre Cícero começou a perder a visão. Percebe-se, nessa narrativa, novamente, que o milagre se faz por algo mais objetivo, "real", uma troca de bebês, do que simplesmente uma ação mágica de transformação de corpos ou concepção mística. Ao mesmo tempo, o extraordinário se interpõe como critério de plausibilidade. O inexplicável só pode ter uma explicação: a ação divina. Dona Romana passa a perder a visão por duvidar da troca dos bebês e Padre Cícero só pode ser Jesus devido aos eventos extraordinários que acontecem ao longo de sua vida.

Mestre José, como pudemos observar, em algumas situações tenta traduzir suas crenças para o que pensa ser aceitável para meu subuniverso, como definido por William James (cf. Schutz 1964). ${ }^{11}$ Em outras palavras, negocia significados para manter a intercomunicação. Mestre José está vendo o mundo mudar ao seu redor, presencia o intenso processo de urbanização e "modernização" de Juazeiro e da Igreja Católica. O conflito ente os subuniversos e sistemas de interpretação está acontecendo logo ali do lado de fora de sua casa. Melhor, logo ali dentro de sua casa, com a minha presença. Consciente do julgamento que se faz de suas crenças, ele articula, inventa, transforma as palavras que acredita terem força de verdade e poder de legitimação. Mas José faz isso tendo por acervo uma cultura local de "causos" e milagres, onde o material, o objetivo, uma cientização através de números e palavras confirmam a verdade dos acontecidos na Terra da Mãe de Deus.

Quando de meu trabalho de campo e até mesmo ao longo da escrita de minha tese eu entendia que mestre José se manteria bem sucedido no seu esforço para traduzir e dialogar entre racionalidades. Num esforço

11 De acordo com Schutz, do fato de experimentarmos a realidade subjetivamente decorre a existência de uma multiplicidade de maneiras de ordenar a realidade, a que Willam James chama de subuniversos - subuniversos da ciência, das idéias, da arte, da religião, etc. (Schutz 1964). 
interpretativo, comparei-o a Dom Quixote, quando este enfrenta um processo de desilusão e tenta um acordo com Sancho Pança (Campos 2004). Mas recusei esse momento da tragédia do cavaleiro da triste figura, preferindo aquele em que ele diz:

Só Deus sabe, responde Dom Quixote, se Dulcinéia vive sobre a terra ou não, se é fantasia ou realidade. Esses assuntos não se podem verificar por completo. A minha senhora não foi por mim engendrada nem tampouco a levo comigo, apesar de contemplá-la na sua forma ideal como alguém que possui todas as qualidades necessárias para que a fama the seja granjeada nos quatro cantos do mundo (cit. em Shutz 1964: 147).

No entanto, mestre José vem a se separar deste mundo logo na virada do ano de 1999 para 2000, quando esperava que o mundo acabasse. Defendi a minha tese em 2001, desconhecia a sua morte. A trajetória de mestre José, ao que parece, mais uma vez o aproxima do cavaleiro da triste figura. Dom Quixote morre de desilusão. Teria José Ave de Jesus sofrido uma desilusão?

Hoje tomaria outra passagem para representar as circunstâncias de sua morte:

"La vida es Sueño: que Deus os perdoe, meus amigos", diz Dom Quixote, "por terem me privado da mais doce existência e da mais esplendorosa visão que qualquer ser humano jamais gozou ou contemplou. Agora tenho certeza de que os prazeres dessa vida se vão como se fossem sombra ou sonho" (cit. em Shutz 1964: 156).

\section{BIBLIOGRAFIA}

BARLEY, Nigel, 1983, Symbolic Structures: An Exploration of the Culture of Dowayos. Londres e Cambridge, Cambridge University Press.

CAMPOS, Roberta Bivar C., 2001, When Sadness is Beautiful: A Study of the Place of Rationality and Emotions within the Social Life of the Ave de Jesus. St. Andrews, St. Andrews University, tese de doutorado.

—, 2004, "Quando o final dos tempos chegar: o uso de uma linguagem apocalíptica e negociação de significados entre os Ave de Jesus”, em L. Musumeci (org.), Antes do Fim do Mundo. Rio de Janeiro, UFRJ, 144-166.

ClASTRES, Pierre, 1995, The Land without Evil: Tupi-Guarani Prophetism. Urbana e Chicago, Universidade de Illinois. 
CLIFFORD, James, 2002, A Experiência Etnográfica. Rio de Janeiro, UFRJ.

CLIFFORD, James, e George E. MARCUS (orgs.), 1986, Writing Culture: The Poetics and Politics of Ethnography. Berkeley e Los Angeles, University of California Press.

COHEN, Anthony, e Nigel RAPPORT (orgs.), 1995, Questions of Consciousness. Londres, Routledge.

CRISTO REI, João de, s/d., «Nascimento de Padrinho Cícero e a troca misteriosa das crianças», folheto popular de cordel, Juazeiro do Norte - CE, imp. Lira Nordestina.

CSORDAS, Thomas J., 1996, The Sacred Self. Berkeley, Los Angeles e Londres, University of California Press.

ELIADE, Mircea, 1996, Imagens e Símbolos: Ensaio sobre o Simbolismo Mágico-Religioso. São Paulo, Martins Fontes.

FERNANDEZ, James W., 1995, "Amazing Grace: meaning deficit, displacement and new consciousness in expressive interaction", em Anthony Cohen e Nigel Rapport (orgs.), Questions of Consciousness. Londres, Routledge, 21-40.

LATOUR, Bruno, 2002, Sobre Fetiches e Deuses. Bauru, Sagrado Coração.

— - 2008, Jamais Fomos Modernos: Ensaio de Antropologia Simétrica. São Paulo, Editora 34.

LEACH, Edmund, 1996, Sistemas Políticos da Alta Birmânia. São Paulo, EDUSP.

LÉVI-STRAUSS, Claude, s/d., Mito e Significado. Lisboa, Edições 70.

— 1989 [1962], O Pensamento Selvagem. Campinas, Papirus.

Merleau-PONTY, Maurice, 1999, Fenomenologia da Percepção. São Paulo, Martins Fontes.

OVERING, Joanna (org.), 1985, Reason and Morality. Londres, Tavistock.

PARKIN, David, 1984, "Political language", Annual Review of Anthropology, 13: 345-365.

SAHLINS, Marshall, 1999, Ilhas de História. Rio de Janeiro, Jorge Zahar Editor.

—, 2004, "Experiência individual e ordem cultural”, em Marshall Sahlins, Cultura na Prática. Rio de Janeiro, Editora UFRJ, 301-316.

SCHUTZ, Alfred, 1964, Collected Papers, II: Studies in Social Theory. Haia, Martinus Nijhoff.

SLATER, Candice, 1986, Trail of Miracles: Stories from a Pilgrimage in Northeast Brazil. Berkeley e Los Angeles, University of California Press.

SNOW, David, et al., 1986, "Frame alignment processes", American Sociological Review, 51: 464-481.

STEIL, Carlos Alberto, 1996, O Sertão das Romarias. Petrópolis, Vozes.

VELHO, Otávio, 1995, Besta-Fera. Rio de Janeiro, Relume-Dumará.

VIVEIROS DE CASTRO, Eduardo, 2002, “O nativo relativo”, Mana, 8 (1): 1 13-148.

Telling "histories" ("causos") and negotiation of meaning and truth among The Ave de Jesus, Juazeiro do Norte - CE - Roberta Bivar C. Campos - Universidade Federal de Pernambuco • robertabivar@gmail.com

This article is based on the ethnographic case of the Ave de Jesus, a group of penitents in Northeastern Brazil. It focuses on the debate about the negotiation of meaning and truth between the researcher and his/her object. The classic anthropological subject of beliefs and rationality is approached but the discussion is widened to include the particular interlocutory space generated in the relationship between researcher and subject, as it contributes to the definition of the situational context for the construction of meaning.

KEYWORDS: narratives, negotiation of meaning and truth, interlocution, dialogue. 